\title{
The predictors of Gastroesophageal Reflux Disease among University students: A cross sectional study in the western region of Saudi Arabia. Gamal Mohamed Hasan Elnemr ${ }^{1,2}$, Abdullah Hassan Almuntashiri ${ }^{1}$, Saud Abdulaziz Alghamdi ${ }^{1}$, Fahad Rajallah Alharthi ${ }^{1}$, Ibrahim Masoodi ${ }^{1}$
}

\author{
1. Department of Internal Medicine, Faculty of Medicine, Taif University, KSA, 2. Department of \\ Medical and Radiological Researches, Nuclear Materials Authority, Egypt. \\ Corresponding author: Ibrahim Masoodi, Email: ibrahimmasoodi@ yahoo.co.in, Phone number: +966531507399
}

\begin{abstract}
Background: Gastroesophageal reflux disease (GERD) is one of the most common health problems that cause a financial burden on healthcare systems worldwide. The prevalence of GERD in Saudi Arabia is steadily increasing. There is a paucity of data regarding GERD among University students.

Material and Methods: This cross-sectional observational study was conducted to assess the prevalence of GERD among male students of Taif University in the western region of Saudi Arabia in addition to determining the risk factors associated with the occurrence of GERD. Data were collected through a selfadministration questionnaire. In addition, weight and height were measured to calculate the body mass index (BMI) of participating students.

Results: Of 464 students who participated from different colleges of the University; More than half of the male students in Taif University $(53.2 \%, 95 \% \mathrm{CI}=48.7 \%$ to $57.8 \%)$ suffer from GERD. There was higher prevalence among smokers, overweight and obese students, those who drink plenty of soft drinks. Students with hypertension, psychiatric diseases, diabetes mellitus, asthma or irritable bowel syndrome had higher prevalence of reflux. GERD was significantly present among students with history of psychological stress. Conclusion: Special consideration should be given to raising the awareness of about gastro esophageal reflux disease among the public and its controllable risk factors. The psychological stress among University students needs to be tackled to decrease reflux among them.
\end{abstract} Keywords: Gastroesophageal reflux disease, Stress, Smoking, obesity, NSAIDs.

\section{INTROUDCTION}

Gastroesophageal reflux disease (GERD) is considered as the most common gastroenterology-related disease among outpatients. Its prevalence is steadily rising throughout the world ${ }^{1,2}$. The disease is associated with restricted activity and missed working days which imposes a significant financial burden for healthcare systems in addition to the costs of management of symptoms ${ }^{3}$. The symptom complex in GERD is either typical which includes heartburn, regurgitation, and dysphagia or atypical mostly extra-esophageal symptoms, such as coughing, chest pain, and wheezing in most of the patients. The esophagus functions as an ante grade pump, the lower esophageal sphincter (LES) as a valve, and the stomach as a reservoir. Various mechanisms postulated in the pathogenesis of GERD are poor esophageal motility decreasing the clearance of acidic material or a dysfunctional LES allowing reflux of large amounts of gastric juice and delayed gastric emptying which is known to increase the volume and pressure in the reservoir until the valve mechanism is defeated, leading to GERD. Usually a combination of these mechanisms is the cause of GERD in a given person. The transient relaxation of the lower esophageal sphincter being the most common mechanism, permanent LES relaxation, and transient increase of intraabdominal pressure that overcomes the LES pressure have been described to be other mechanism of LES dysfunction leading to GERD.

The most serious complication of longstanding or severe GERD is the development of Barrett esophagus present in $8-15 \%$ of patients with GERD ${ }^{4}$. Barrett esophagus is thought to be 
caused by the chronic reflux of gastric juice into the esophagus. Barrett esophagus with intestinal type metaplasia has malignant potential and is a risk factor for the development of esophageal adenocarcinoma increasing the risk of adenocarcinoma 30-40 times ${ }^{4}$. Thus GERD management is akin to nip the evil in the bud.

A cross-sectional study conducted in 2,043 participants to estimate the prevalence of GERD in the Saudi community revealed the prevalence of GERD to be $28.7 \%^{5}$ In another study, the prevalence of GERD in Riyadh among 1265 individuals based on GERDQ score was $45.4 \%$ and a higher prevalence among older individuals, those with higher BMI, and smokers was noted ${ }^{6}$.

Worldwide smoking, BMI, male gender depression and anxiety etc. were revealed to be the risk factors for gastroesophageal reflux symptoms. Persisting gastroesophageal reflux disease (GERD) symptoms affect mental state and social activities and mental disorders likewise play a crucial role on GERD symptoms ${ }^{7}$. It will be prudent to mention that a high prevalence of depression and stress symptoms have been found among university students in a study by Bayram et al. ${ }^{8}$. Authors of the same study concluded that there is a need for primary and secondary prevention measure and support services for this group of students. There is limited data regarding stress and GERD in Saudi Arabia among University students hence we were promoted to undertake this study among university students based on a well defined questioner following the Montreal classification of GERD 9 .

\section{Materials and Methods}

\section{Study design:}

This was a cross sectional observational study conducted to assess the prevalence of GERD among male students of Taif University in Taif City, Saudi Arabia .The study was carried out from November 2017 to March 2018. The study was also done to determine the risk factors associated with the occurrence of GERD with special reference to anxiety and depression.

\section{Data collection:}

Data were collected through a selfadministration questionnaire. In addition, weight and height were measured to calculate the body mass index (BMI) of participating students. Each student included in the study was asked to fill the self-administered structured questionnaire (after receiving initial training). A total of 464 students from different colleges and academic years responded to the questionnaire.

The questionnaire was designed to know the following information:

1. Socio-demographic data: e.g., age, nationality, college, and per capita monthly income in Saudi Riyal.

2. Factors related to special habits: e.g., smoking status i.e., smoker or non-smoker, physical activity, lying down straight after eating, sleeping immediately after eating, chewing for enough time.

3. Factors related to dietary habits: fast food, tea, coffee, soft drinks, and drinking enough water.

4. Related diseases, heart burn, difficulty or pain during swallowing, allergy to spicy greasy food, indigestion or colon problems, and stress.

5. Factors of stress, mood and any depressive symptoms, lack or disturbed sleep etc.

Each studied student's BMI = weight in $\mathrm{kg} / \mathrm{h}$ eight in $\mathrm{m}^{2}$ was calculated. According to BMI, students were classified into 4 categories according to WHO, 1998 (10) under-weight (BMI < 18.5 $\left.\mathrm{kg} / \mathrm{m}^{2}\right)$, normal weight $\left(\mathrm{BMI}=18.5-24.9 \mathrm{~kg} / \mathrm{m}^{2}\right)$, over-weight $\left(B M I=25-29.9 \mathrm{~kg} / \mathrm{m}^{2}\right)$, and obese $\left(B M I \geq 30 \mathrm{~kg} / \mathrm{m}^{2}\right)$ students.

\section{Statistical analyses:}

Data were statistically described in terms of frequencies (number of cases) and valid percentages for categorical variables. Mean, standard deviations, minimum and maximum were used to describe numerical variable (median and inter-quartile range (IQR) were considered for non-parametric data). 
Comparison of categorical variables between the subgroups (cross-tabulation) was done using Chisquare test. $\mathrm{P}$ values less than 0.05 were considered statistically significant. All statistical calculations were done using computer program IBM SPSS (Statistical Package for the Social Science; IBM Corp, Armonk, NY, USA) release 21 for Microsoft Windows.

\section{Ethical considerations:}

During the research activities, each student was informed about the study objectives with emphasis from our team on confidentiality of the collected data and results, and also on getting consent for participation in the study.

\section{Results \\ Descriptive Analysis \\ Socio-demographic characteristics: \\ Nationality}

A total of $464(100 \%)$ male students from Taif University, Saudi Arabia participated in this cross-sectional study including 457 (98.5\%) Saudi and 7 (1.5\%) non-Saudi students.

Age

The mean \pm SD age of participating students was $21.6 \pm 2$ years with a minimum value of 16 and a maximum value of 32 years. Students were classified into 3 categories based on their age. The largest category included students aged 21 to 25 years (306 students, 65.9\%), followed by students aged 16 to 20 years (144 students, $31.0 \%$ ) and the smallest group included students aged 26 years and more (14 students, 3.0\%).

\section{Family monthly income:}

Students were asked about the monthly income of their family and it was found that the income of $135(29.1 \%)$ families was less than 5000 SR, which of 125 (26.9\%) families was 5000 to 1000 SR, which of $78(16.8 \%)$ families was 10000 to 15000 SR while the income of 126 (27.2\%) families was more than $15000 \mathrm{SR}$.

\section{Special habits:}

\section{Smoking status:}

Data on smoking status were collected and the majority, $338(72.8 \%)$ students, said that they are non-smokers while $126(27.2 \%)$ students were smokers. Number of cigarettes smoked per day ranged from 1 to 60 cigarettes/day with a median (IQR) value of 15 (12) cigarettes/ day while number of smoking years ranged from 1 to 20 years with a median (IQR) value of 4 (3.0) years.

Physical activity

Regarding exercising after eating meals, 338 $(72.8 \%)$ student said that they don't exercise after eating, $50(10.8 \%)$ students said that they sometimes do while $76(16.4 \%)$ said that they exercise after eating their meals.

Lying down straight after eating When asked if they prefer lying down on the couch straight after eating, $136(29.3 \%)$ students said that they never do so, $201(43.3 \%)$ students said that they sometimes do so while $47(10.1 \%)$ said that they prefer lying down on the couch straight after eating.

Sleeping immediately after eating

One third of the students (155 students, 33.4\%) said that they don't go to bed immediately after eating, $85(18.3 \%)$ said that they sometime do so while $224(48.3 \%)$ of the students said that they go to bed in the evening immediately after eating.

Chewing for enough time

Regarding taking enough time to eat and chew food well, $86(18.5 \%)$ students said that they do not do so, $144(31.0 \%)$ said that they sometimes do and this may depend on the type of food while half of the students, 234 (50.4\%), said that they take enough times to eat and chew food well.

\section{Dietary habits \\ Fast food:}

Students were asked how frequently they eat fast food. Thirty students $(6.5 \%)$ said that they don't eat fast food at all, 127 (27.4\%) said that they eat fast food once per week, $95(42.0 \%)$ said that they eat fast food 2 to 3 times per week while 112 students $(24.1 \%)$ said that they eat fast food 4 to 7 times per week.

Drinking plenty of tea and coffee:

Regarding caffeine intake, 97 (20.9\%) students said that they don't drink plenty of tea and coffee, $211(45.5 \%)$ said that they sometimes do so while 
$156(33.6 \%)$ students said that they drink plenty of tea and coffee.

Soft drinks:

Regarding soft drinks, 142 (30.6\%) students said that they don't drink plenty of soft drinks, 190 $(40.9 \%)$ said that they sometimes do so while 132 $(28.4 \%)$ students said that they drink plenty of soft drinks.

Drinking enough water:

Around a quarter of the students (120 students, $25.9 \%$ ) reported that they don't drink enough water after every meal, 147 (31.7\%) students said that they sometimes do so while 197 (42.5\%) said that they drink enough water after every meal.

\section{Medical history and related disease:}

\section{Concomitant diseases:}

Of 464 students, 377 (81.3\%) said that they were not suffering from any disease while $87(18.8 \%)$ students reported suffering from different diseases. The most frequently reported disease was high blood pressure as reported in 19 (4.1\%) students, followed by diabetes mellitus as reported in 15 (3.2\%) students, psychiatric diseases, asthma and high blood lipids were reported in $8(1.7 \%)$ students for each and irritable bowel syndrome was reported in 6 $(1.3 \%)$ students.

\section{Manifestations:}

In addition to the previously mentioned diseases, students were asked if they suffer from specific manifestations where 100 (21.6\%) students said that they suffer from dental erosion, $49(10.6 \%)$ said that they have sinusitis, $16(34.6 \%)$ said that they suffer from sore throat, $12(2.6 \%)$ reported suffering from chronic cough, $11(2.4 \%)$ reported suffering from sleep apnea, $10(2.2 \%)$ said that they suffer from hoarseness of voice, while blocked nose and calcium deficiency were reported in one $(0.2 \%)$ patient for each while 264 (56.9\%) students said that they don't suffer from any of these manifestations.

Difficulty or pain during swallowing:

The majority of students (385 students, $83.0 \%$ ) said that they don't feel difficulty or pain during swallowing, $32(6.9 \%)$ said that they feel so sometimes while $47(10.1 \%)$ students feel difficulty or pain during swallowing.
Allergy to spicy or greasy food:

Almost two thirds of the participants (301 students, $64.9 \%$ ) reported that they don't have allergy to any type of food, 90 (19.4\%) students said that they sometimes experience allergy to some types of food and $73(15.7 \%)$ students said that they have allergy to certain types of food such as spicy or greasy food.

Stomach problems such as indigestion:

Most of the students (287 students, 61.9\%) reported that they don't have any stomach problems such as indigestion, $32(6.9 \%)$ said that they sometimes suffer from stomach problems while $72(15.5 \%)$ reported that they have stomach problems such as indigestion.

\section{Stress}

Of 464, $189(40.7 \%)$ students said that they don't feel stressed, 134 (28.9\%) sometimes feel stressed while $141(30.4 \%)$ reported that they feel stressed. None of the study subjects had features of major depression.

\section{Body Mass Index (BMI):}

The mean \pm SD body weight was $75.5 \pm 20.0 \mathrm{~kg}$ and the mean \pm SD height was $170.6 \pm 11.2 \mathrm{~cm}$. Body Mass Index (BMI) was calculated for all students using the formula $(\mathrm{BMI}=$ weight in $\mathrm{kg} /$ height in $\mathrm{m}^{2}$ ) where the mean $\pm \mathrm{SD}$ value was found to be $25.9 \pm 7.1 \mathrm{~kg} / \mathrm{m}^{2}$.

According to WHO, 1998 criteria students were classified into 4 categories based on their BMI including under-weight (BMI $<18.5 \mathrm{~kg} / \mathrm{m}^{2}$ ), normal weight $\left(\mathrm{BMI}=18.5-24.9 \mathrm{~kg} / \mathrm{m}^{2}\right)$, overweight $\left(\mathrm{BMI}=25-29.9 \mathrm{~kg} / \mathrm{m}^{2}\right)$, and obese $(\mathrm{BMI}$ $\left.\geq 30 \mathrm{~kg} / \mathrm{m}^{2}\right)^{10}$

The largest category included students with normal weight (186 students, 40.1\%). This was followed by obese students (118 students, 25.4\%), over-weight students (106 students, $22.8 \%$ ) and under-weight students (54 students, $11.6 \%)$. Table 1 


\section{Primary objective: prevalence of GERD among participating students:}

To estimate the prevalence of GERD among participating students, they were asked if they suffer from heartburn (acidity) and how frequently they suffer from it. Nearly less than half of the students (217 students, 46.8\%) said that they don't suffer from heartburn at all while 247 students $(53.2 \%, 95 \% \mathrm{CI}=48.7 \%$ to $57.8 \%)$ said that they suffer from heartburn with different frequencies.

Almost one quarter of the students (119 students, $25.6 \%$ ) reported that they experience heartburn once per week, $62(13.4 \%)$ students said that they experience heart burn 2 to 3 times per week, 36 $(7.8 \%)$ students said that they experience heart burn 4 to 7 times per week while $30(.65 \%)$ students said that they experience heart burn more than once per day.

Secondary objective: risk factors related to the occurrence of GERD:

\section{Socio-demographic characteristics:}

Prevalence of GERD among subgroups of students with different socio-demographic characteristics was compared. The prevalence didn't differ significantly between the different age groups $(\mathrm{p}=0.404)$. Nationality $(\mathrm{p}=0.260)$ and family monthly income $(\mathrm{p}=0.811)$ that were shown to have no effect on the prevalence of GERD. Table 1

Body Mass Index:

Students were categorized into 4 groups according to their BMI and the prevalence of GERD among the different subgroups was compared. It was fond that the prevalence among obese students $(64.4 \%)$ was significantly higher $(\mathrm{p}=0.002)$ than that among overweight $(57.5 \%)$, normal weight $(48.9 \%)$ and underweight students (35.7\%).Table 1

\section{Smoking}

The prevalence of GERD among smokes (68.3\%) was significantly higher $(\mathrm{p}<0.001)$ than that among non smokers (47.6\%). Figure 2

\section{Physical activity}

Prevalence of GERD didn't differ significantly between students who exercise after eating their meals and those who don't exercise $(\mathrm{p}=0.916)$.

\section{Lying down straight after eating:}

Prevalence of GERD among students who prefer lying down on the couch straight after eating their meals $(51.2 \%)$ was significantly higher $(\mathrm{p}<0.001)$ than that among students who don't do so $(41.2 \%)$. The same was observed for the prevalence among students who sometimes lye on the couch after eating $(62.7 \%)$ that was significantly higher $(\mathrm{p}<0.001)$ than the rate among students who don't (41.2\%). (Figure 1)

\section{Sleeping immediately after eating:}

Prevalence of GERD among students who sleep immediately after eating in the evening $(57.1 \%)$ was significantly higher $(\mathrm{p}<0.001)$ than that among students who don't do so $(40.0 \%)$. The same was observed for the prevalence among students who sometimes sleep immediately after eating $(67.1 \%)$ that was significantly higher $(\mathrm{p}<0.001)$ than the rate among students who don't $(40.0 \%)$.

\section{Chewing for enough time}

On the other hand, prevalence of GERD didn't differ significantly between students who take enough time to eat and chew their food well, those who sometimes do and those who don't $(\mathrm{p}=0.222)$.

Dietary habits:

\section{Fast food}

Frequency of eating fast food wasn't revealed to affect the prevalence of GERD $(\mathrm{p}=0.903)$

Tea and coffee intake

The frequency of tea and coffee intake was not found to affect the prevalence of GERD $(\mathrm{p}=0.530)$.

\section{Soft drinks intake}

On the other hand, drinking plenty of soft drinks was associated with higher prevalence of GERD. The prevalence among students who usually drink plenty of soft drinks (60.5\%) was significantly higher $(\mathrm{p}=0.004)$ than that among students who sometimes drink soft drinks 
$(54.5 \%)$ and those who don't drink soft drinks $(42.3 \%)$.

\section{Drinking enough water after meals}

Drinking enough water after meals was found to have no effect on prevalence of GERD ( $\mathrm{p}=0.564)$.

Medical history:

\section{Concomitant diseases}

Prevalence of GERD among students who had some other diseases (72.4\%) was significantly higher $(\mathrm{p}<0.001)$ than the rate among students who didn't have any other diseases (48.8\%).

For example, the prevalence of GERD among students with high blood lipids (100\%), high blood pressure $(84.2 \%)$, psychiatric diseases $(75.0 \%)$, diabetes mellitus $(66.7 \%)$, irritable bowel syndrome (66.7\%) and asthma (50\%) was significantly higher $(p=0.024)$ than the prevalence among students who don't have any diseases $(48.8 \%)$.

\section{Manifestations}

Students were asked if they suffer from specific manifestations such as chronic cough, sore throat, hoarseness of voice, sinusitis, dental erosion and sleep apnea. In general, students who had one or more of these manifestations were found to have a significantly higher $(\mathrm{p}<0.001)$ prevalence of GERD $(64.9 \%)$ compared to those who don't have any of these manifestations (44.3\%).

For example, the prevalence among students who have chronic cough $(83.3 \%)$, sore throat $(75.0 \%)$, hoarseness of voice $(70.0 \%)$, sinusitis $(67.3 \%)$, sleep apnea (63.6\%) and dental erosion (59.0\%) were significantly higher than the prevalence among students who have none of these manifestations (44.3\%).

\section{Difficulty or pain during swallowing}

The prevalence of GERD among students who feel difficulty or pain during swallowing $(78.1 \%)$ was significantly higher $(p=0.007)$ than that among students who sometimes feel pain or difficulty (59.6\%) and those who don't feel difficult or pain during swallowing (50.4\%).

\section{Stomach problems such as indigestion}

Students with stomach problems such as indigestion showed significantly higher $(\mathrm{p}<0.001)$ prevalence of GERD $(68.6 \%)$ compared to students who sometimes have stomach problems $(61.1 \%)$ and those who don't have stomach problems (45.6\%).

\section{Allergy to spicy or greasy food}

Students with allergy to spicy or greasy food showed significantly higher $(\mathrm{p}=0.017)$ prevalence of GERD (64.4\%) compared to students who sometimes have such allergies $(58.9 \%)$ and those who don't have allergies $(48.5 \%)$.

\section{Stress}

Stress was found to be associated with high prevalence of GERD. Students who are always stressed showed significantly higher $(\mathrm{p}<0.001)$ prevalence of GERD (67.9\%) compared to those who are sometimes stressed $(56.0 \%)$ and those who are not always not stressed (40.7\%).

\section{Figure 1: Effect of smoking on GERD}

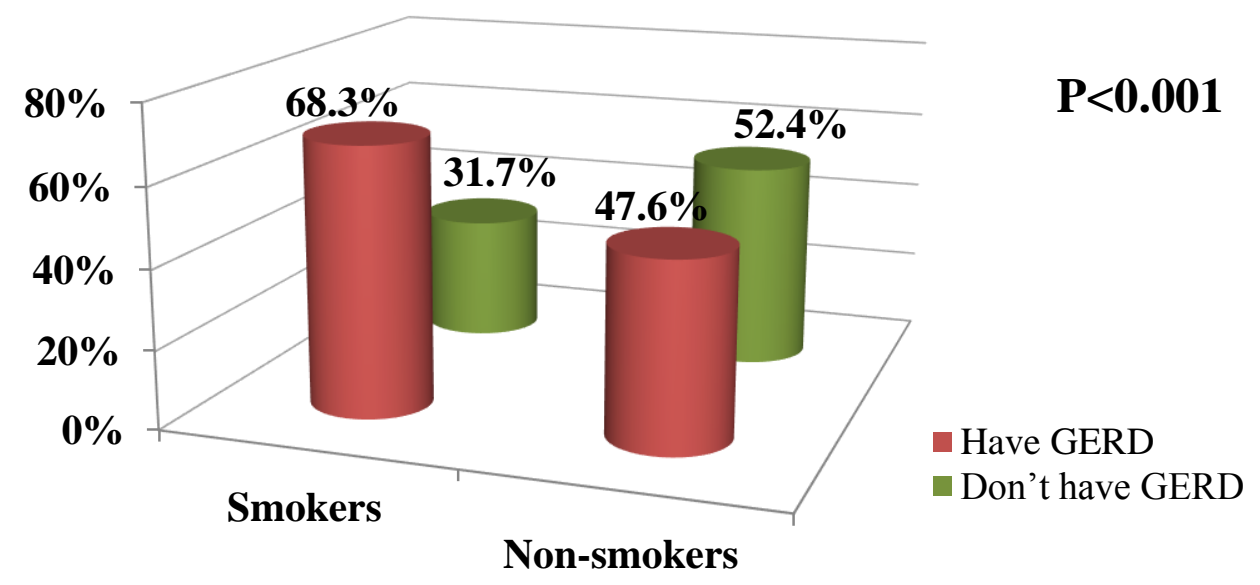


The predictors of Gastroesophageal Reflux Disease.....

\begin{tabular}{|c|c|c|}
\hline Variable & $\mathrm{N}=464$ All males & $\begin{array}{l}\text { Prevalence GERD } \\
\text { (P value ) }\end{array}$ \\
\hline \multirow{3}{*}{ 1. Socioeconomic status } & Upper $78(16.8 \%)$ & \multirow{3}{*}{$\mathrm{p}=0.811$} \\
\hline & Middle125 (26.9\%) & \\
\hline & Lower $135(29.1 \%)$ & \\
\hline \multirow{3}{*}{$\begin{array}{l}\text { 2. Lying down straight after } \\
\text { eating }\end{array}$} & No $136(29.3 \%)$ & \multirow{3}{*}{$\mathrm{p}<0.001$} \\
\hline & Yes $201(43.3 \%)$ & \\
\hline & Occasional $47(10.1 \%)$ & \\
\hline \multirow{3}{*}{$\begin{array}{l}\text { 3. Sleeping immediately after } \\
\text { eating }\end{array}$} & No 155 students, $33.4 \%$ ) & \multirow{3}{*}{$\mathrm{p}<0.001$} \\
\hline & Occasional, $85(18.3 \%)$ & \\
\hline & Yes $224(48.3 \%)$ & \\
\hline \multirow{3}{*}{ 4. Chewing for enough time } & No $86(18.5 \%)$ & \multirow{3}{*}{$\mathrm{p}=0.222$} \\
\hline & Occasional $144(31.0 \%)$ & \\
\hline & Yes $234(50.4 \%)$ & \\
\hline \multirow{3}{*}{ 5. Soft drinks } & No $142(30.6 \%)$ & \multirow{3}{*}{$\mathrm{p}=0.004$} \\
\hline & Occasional $190(40.9 \%)$ & \\
\hline & Plenty $132(28.4 \%)$ & \\
\hline \multirow[b]{2}{*}{ 6. Co morbid illness } & No disease $377(81.3 \%)$ & \multirow[t]{2}{*}{$\mathrm{P}<0.001$} \\
\hline & Yes $87(18.8 \%)$ & \\
\hline \multirow{3}{*}{ 7. Pain during swallowing } & No $38583.0 \%$ ) & \multirow[t]{3}{*}{$\mathrm{P}=0.007$} \\
\hline & Occasional Yes $32(6.9 \%)$ & \\
\hline & Yes $47(10.1 \%)$ & \\
\hline \multirow{3}{*}{ 8..Allergy to spicy food } & No $301(64.9 \%)$ & \multirow[t]{3}{*}{$\mathrm{P}=0.017$} \\
\hline & Occasional $90(19.4 \%)$ & \\
\hline & Yes $73(15.7 \%)$ & \\
\hline \multirow{4}{*}{ 9.BMI } & $\begin{array}{l}\text { BMI }<18.5 \mathrm{~kg} / \mathrm{m}^{2} \\
54 \text { students, } 11.6 \%)\end{array}$ & \multirow[t]{4}{*}{$\mathrm{p}=0.002$} \\
\hline & $\begin{array}{l}\mathrm{BMI}=18.5-24.9 \mathrm{~kg} / \mathrm{m}^{2} \\
186 \text { students, } 40.1 \% .\end{array}$ & \\
\hline & $\begin{array}{l}\mathrm{BMI}=25-29.9 \mathrm{~kg} / \mathrm{m}^{2} \text { ) } \\
106 \text { students, } 22.8 \%\end{array}$ & \\
\hline & $\begin{array}{l}\left(\mathrm{BMI} \geq 30 \mathrm{~kg} / \mathrm{m}^{2}\right) \\
118 \text { students }(25.4 \%)\end{array}$ & \\
\hline
\end{tabular}

Table 1 Life style and its association with GERD 


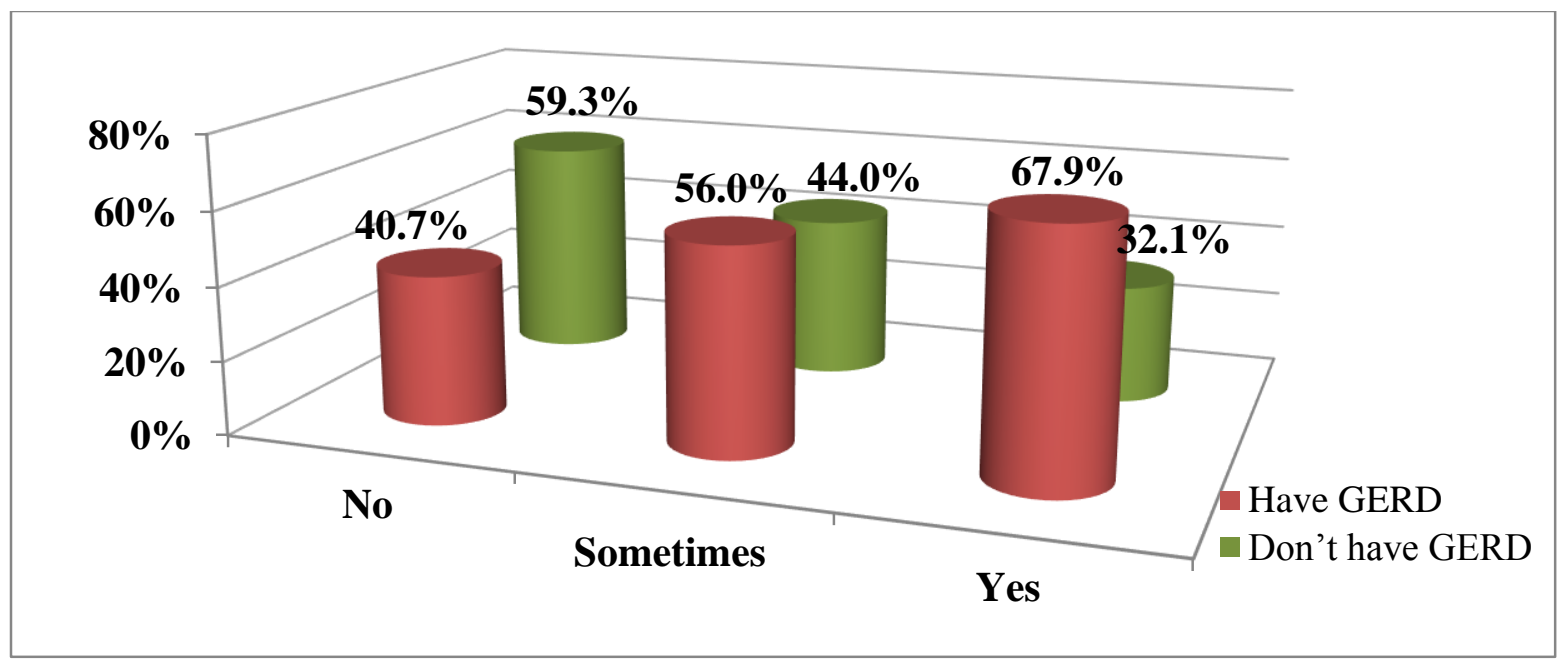

Fig 2 Association of Stress and GERD

\section{Discussion}

Our results showed that more than half of male students in Taif University $(53.2 \%, 95 \%$ $\mathrm{CI}=48.7 \%$ to $57.8 \%$ ) have GERD. Due to changes in environmental conditions, recent epidemiological evidences suggest that the incidence of gastro esophageal reflux disease (GERD) is increasing in both Asian and Western countries $^{10-12}$.

The obesity was found to have a significant effect on GERD as the prevalence of reflux among obese and over-weight students was significantly higher $(\mathrm{p}=0.002)$ than that among normal weight and underweight students as shown in Table 1 . The hypothesis that obesity increases esophageal acid exposure is supported by the documentation of a dose-response relationship between increased BMI and increased prevalence of GERD and its complications $^{13}$. In our study the sociodemographic factors age groups, nationality and family monthly income were revealed to have no significant effect on the prevalence of GERD as shown in the table 1.

In our study the stress levels were significantly associated with GERD as shown in figure 2. It will be prudent to mention that a high prevalence of depression and stress symptoms have been found among university students by Bayram et $\boldsymbol{a l}^{8}{ }^{8}$. Authors of the same study concluded that there is a need for primary and secondary prevention measure and support services for this group of students. The stress has bidirectional effect on GERD .The stress promotes GERD and GERD in turn exacerbates stress. In a study the data on 438 by Chen et al. ${ }^{14}$ have shown that GERD patients exhibit differential levels of psychological symptoms. Long duration of GERD was related to typical plus atypical symptoms well known in GERD. In the aforementioned study patients with more than two years with GERD presented with increased scores in depression and anxiety. Having said this, it is imperative to tackle GERD and stress among University students so that long term complications are averted in this population.

More than two thirds of the participants in our study were aged 21 to 25 years. Although Gastro-esophageal reflux disease is more common among older adults the high prevalence in our study subjects could be explained due to concurrence of multiple risk factors like obesity and most important stress and smoking habits among university students. The prevalence of GERD among smokers (68.3\%) was significantly higher $(\mathrm{p}<0.001)$ than that among non smokers 
(47.6\%) as shown in figure 1. This is comparable to the results of the study by Zheng et al. ${ }^{15}$ who demonstrated increased risk of frequent GERD symptoms by $53 \%$ among male participants compared to nonsmokers. Although majority of students $(72.8 \%)$ were non-smokers in this study but $27.2 \%$ were smokers with a median (IQR) of 15 (12) cigarettes smoked per day for a median (IQR) duration of 4 (3.0) years. Studies in Saudi Arabia have shown that $20-50 \%$ of smokers start smoking at the age of 15 years and relief from psychological tension, boredom, and imitating others (especially friends, siblings, and parents) have been found to be the most important reasons for smoking in Saudi Arabia ${ }^{16,17}$. The Australian data suggest that there is a combined effects of obesity, acid reflux and smoking on the risk of adenocarcinomas of the esophagus ${ }^{18}$ warranting that life style modification should be strongly emphasized among university students in order to nip the evil in the bud.

Higher rates of GERD were observed among students who preferred lying down on the couch soon after eating $(\mathrm{p}<0.001)$ and those who slept immediately after eating in the evening $(p<0.001)$. On the other hand, chewing food for enough time $(p=0.222)$ and exercising after eating $(p=0.916)$ were not found to affect the rate of GERD. The variations in gastroesophageal reflux over $24 \mathrm{~h}$ were analyzed in 220 patients with symptoms suggestive of gastroesophageal reflux disease by Gudmundsson et al. The authors compared it with 50 normal subjects by studying the results obtained by ambulatory $24-\mathrm{h}$ esophageal $\mathrm{pH}$-monitoring. The greatest amount of reflux was seen during the evening period. The pattern was most pronounced in patients with esophagitis ${ }^{19}$. Our results are in coherence with their study but we didn't conduct any ambulatory 24-h esophageal $\mathrm{pH}$-monitoring in this study.

Some dietary habits were studied to explore if they influence the prevalence of GERD in our study cohort. The only factor that was found to affect GERD was drinking plenty of soft drinks. The prevalence among students who usually drink plenty of soft drinks $(60.5 \%)$ was significantly higher $(\mathrm{p}=0.004)$ than those who occasionally consumed soft drinks $(54.5 \%)$ and prevalence was still lower among those who didn't consume soft drinks at all (42.3\%). This is consistent with the results of previous studies suggesting that carbonated beverages can exacerbate symptoms of GERD and dyspepsia ${ }^{20}$. On the contrary to soft drinks, eating fast food $(p=0.903)$, drinking plenty of tea and coffee $(\mathrm{p}=0.530)$ and drinking enough water after meals $(p=0.564)$ were all shown to have no effect of prevalence of GERD in our study.

Medical history of participating students was collected and correlated to the prevalence of GERD. It was found that the prevalence among students with high blood pressure $(84.2 \%)$, psychiatric diseases $(75.0 \%)$, diabetes mellitus $(66.7 \%)$, irritable bowel syndrome $(66.7 \%)$ and asthma $(50 \%)$ was significantly higher $(\mathrm{p}=0.024)$ than the prevalence among students who had no co morbid illnesses (48.8\%) (Figure 1). This is comparable to the results of a previous study that reported a higher risk of GERD among patients with hypertension and those with bronchial asthma ${ }^{21}$. However, the same study reported no relation with diabetes mellitus. In another study it was concluded that most adult asthmatics, regardless of the use of bronchodilator therapy, have abnormal gastroesophageal reflux manifested by increased reflux frequency, delayed acid clearance during the day and night, and diminished lower esophageal sphincter pressures $^{22}$. Students with allergy to spicy or fatty food showed significantly higher $(\mathrm{p}=0.017)$ prevalence of GERD compared to students who didn't have such allergies. This supports the evidence that fatty food can exacerbate symptoms of GERD ${ }^{23}$.

The strong point in our study is that we studied GERD in the young population with multiple risk factors especially their predisposition to stress, which is well documented among university students. In a study by Thrift et al. it was observed that the age of onset of GERD is very important as GERD at younger age with at least reflux once weekly has been linked to the risk of development of Barrett's esophagus making the results of this study very important ${ }^{24}$. 
The drawback of our study is that an endoscopic procedure and ambulatory 24-h esophageal $\mathrm{pH}$-monitoring were not carried out in the study subjects with features of GERD .Nevertheless, none of our study subjects had nausea, vomiting, or regurgitation that would have alerted us to evaluate for delayed gastric emptying so no further testing was done in our study population.. Further, when endoscopic esophageal mucosal breaks and 24-h $\mathrm{pH}$ data were used as criteria for the diagnosis of GERD Carlsson et al. $^{25}$ compared the usefulness of a structured questionnaire in the assessment of symptomatic gastroesophageal reflux disease. The authors observed that the questionnaire had a sensitivity of $92 \%$ but a very low specificity of $19 \%$ so we could postulate that this study identified significant cases of GERD and various positive risk factors thereof.

\section{Conclusion}

From the discussed results, we can conclude that more than half of male students in Taif University suffer from GERD highlighting an increased trend in this cohort. Based on our results we may affirm that the life style modification and promotion of health education in University needs to be a top priority. In addition, there is a need for primary and secondary prevention measures to combat stress among university students, with the development of adequate and appropriate support services for this group.

\section{Acknowledgments:}

We extend our sincere thanks to following data collectors for their help during data collection required in this study 1-Abdulsalam Saleh Almalki 2-Yousef Abduljabbar Alzilfi 3-Sulaiman Althobaiti , 4. Fahad Mohammed Saad Alzahrani and 5-Razan Abdulkareem Alsini

\section{References}

1. Peery A, Dellon E, Lund J, Crockett S, McGowan C, Bulsiewicz W et al.(2012): Burden of Gastrointestinal Disease in the United States: $2012 \quad$ Update. Gastroenterology,143(5):1179 1187.

2. El-Serag H(2007): Time Trends of Gastroesophageal Reflux Disease: A Systematic Review. Clinical Gastroenterology and Hepatology,5(1):17-26.

3. Camilleri M, Dubois D, Coulie B, Jones M, Kahrilas P, Rentz A et al.(2005): Prevalence and Socioeconomic Impact of Upper Gastrointestinal Disorders in the United States: Results of the US Upper Gastrointestinal Study. Clinical Gastroenterology and Hepatology,3(6):543-552.

4. Howard Hampel, Neena S. Abraham, Hashem B et al .(2005): Meta-Analysis: Obesity and the Risk for Gastroesophageal Reflux Disease and Its Complications. Ann Intern Med. ,143(3):199-211

5. Alsuwat O, Alzahrani A, Alzhrani M, Alkhathami A et al. (2018): Prevalence of Gastroesophageal Reflux Disease in Saudi Arabia. Journal of Clinical Medicine Research, 10(3):221-225

6. Almadi MA, Almousa MA, Althwainy AF et al.(2014): Prevalence of symptoms of gastroesopahgeal reflux in a cohort of Saudi Arabians: a study of 1265 subjects. Saudi J Gastroenterol. ,20(4): 248-54

7. Zhang L, Tu L, Chen J, Song J et al. (2017): Health-related quality of life in gastroesophageal reflux patients with noncardiac chest pain: Emphasis on the role of psychological distress. World J Gastroenterol. ,23(1):127-134.

8. Bayram N, Bilgel $\mathbf{N}$ et al. (2008): The prevalence and socio-demographic correlations of depression, anxiety and stress among a group of university students. Soc Psychiatry Psychiatr Epidemiol. ,43(8):667-72. 
9. Vakil N, van Zanten SV, Kahrilas P, Dent J et al. (2006): The Montreal definition and classification of gastroesophageal reflux disease: a global evidence-based consensus. Am J Gastroenterol. ,101(8):1900-20

10. World Health Organization (1998): Obesity: preventing and managing the global epidemic. Report of World Health Organization Consultation, apps.who.int/iris/handle/10665/63854

11. Katz PO, Gerson LB et al. (2013): Guidelines for the diagnosis and management of gastroesophageal reflux disease. Am J Gastroenterol. ,108(3):308-28

12. Fock KM, Talley N, Goh KL et al. (2016): Asia-Pacific consensus on the management of gastro-oesophageal reflux disease: an update focusing on refractory reflux disease and Barrett's oesophagus. Gut ,65(9):1402-15

13. Erridge S, Moussa OM, Ziprin $P$ et al. ( 2018): Risk of GERD-Related Disorders in Obese Patients on PPI Therapy: a Population Analysis. Obes Surg. ,28(9):2796-2803

14. Chen X, Li P, Wang F, Ji G, Miao L et al. (2017): Psychological Results of 438 Patients with persisting Gastroesophageal Reflux Disease Symptoms by Symptom Checklist 90-Revised Questionnaire. Euroasian J HepatoGastroenterol. ,7(2):117-121.

15. Zheng $Z$, Nordenstedt $H$, Pedersen $N$, Lagergren J et al. (2007): Lifestyle Factors and Risk for Symptomatic Gastroesophageal Reflux in Monozygotic Twins.Gastroenterology, 132(1):87-95.

16. Al-Damegh SA, Saleh AS, Al-Alfi MA et al. (2004): Cigarette smoking behavior among male secondary school students in the central region of Saudi Arabia. Saudi Med J.,25(2):2159.
17. Al-Yousaf MA et al. (2001): Prevalence of smoking among high school students. Saudi Med J. ,22: 872-874

18. Whiteman DC, Sadeghi S, Pandeya $\mathrm{N}$ et al. (2008): Combined effects of obesity, acid reflux and smoking on the risk of adenocarcinomas of the oesophagus. Gut ,57(2):173-180.

19. Gudmundsson K, Johnsson F, Joelsson B et al. (1988): The time pattern of gastroesophageal reflux. Scand J Gastroenterol. ,23(1):75-9.

20. Cuomo R, Sarnelli G, Savarese M et al. (2009): Carbonated beverages and gastrointestinal system: Between myth and reality. Nutrition, Metabolism and Cardiovascular Diseases,19(10):683-689

21. Nandyal S, Suria S, Chogtu B et al. (2017): Risk of GERD with Diabetes Mellitus, Hypertension and Bronchial Asthma - A Hospital based Retrospective Cohort Study. J Clin Diagn Res. ,11(7):OC25-OC29.

22. Sontag SJ, O'Connell S, Khandelwal S et al. ( 1990): Most asthmatics have gastroesophageal reflux with or without bronchodilator therapy.

Gastroenterology,99(3):613-20

23. Jarosz M et al .(2014): Risk factors for gastroesophageal reflux disease: the role of diet. Prz Gastroenterol. ,9(5):297-301.

24. Thrift AP, Kramer JR, Qureshi $Z$ et al. (2013): Age at onset of GERD symptoms predicts risk of Barrett's esophagus. Am J Gastroenterol. ,108(6):915-22.

25. Carlsson R1, Dent J, Bolling-Sternevald E et al. (1998): The usefulness of a structured questionnaire in the assessment of symptomatic gastroesophageal reflux disease. Scand J Gastroenterol. ,33(10):1023-9. 